\title{
Exploring the role of computers in sex and relationship education within British families
}

Triece Turnbull PhD, Paul van Schaik $\mathrm{PhD}$ and Anna van Wersch $\mathrm{PhD}$ School of Social Sciences and Law, Teesside University, Middlesbrough, TS1 3BA, United Kingdom

\section{Corresponding author:}

Dr Triece Turnbull, C.Psychol, C.Sci, AFBPsS, Health Psychologist (HPC).

5 Barlow Close

Hunters Hill

Guisborough

Cleveland

TS14 7LF

United Kingdom

Email: trieceturnbull@yahoo.co.uk

Running heading : Using computers for sex and relationship education 


\section{Introduction}

The biggest media contributor to discussions and what children learn about sexual matters has been found to be the World Wide Web (WWW) (Foster-Cox, Scharer \& Clark, 2009). In 2007, nearly sixteen million homes in the UK had computers, which equates to potentially $65 \%$ of all households having access to the Internet (Office for National Statistics, 2008). Although the Internet can be a useful source for accessing different types of educational information, the words 'sex' and 'porn' have been the most searched for words since 1999 (Richardson, 2009). The UK Council for Child Internet Safety revealed that on average two thirds of 13 to 17 year olds in the UK have viewed pornographic material and one third used pornographic material to learn about sex and women's bodies (Johnson, 2008). It would appear that pornography is not difficult to access as there are 420 million pornographic pages on the Internet (Richardson, 2009). As a consequence, pornography generates millions of pounds a year through displaying explicit material (Richardson, 2009). However, concerns have been raised, as it is hard to regulate content on the WWW, leading to easy viewing of pornography for all (Haggstrom-Nordin, Sandberg \& Hanson, 2006). Although criticisms of the WWW focus towards aspects of pornography and related subjects (e.g. cybersex and sex crimes), the WWW has become a popular medium for communication.

Social-networking on the WWW, such as Facebook, Twitter, Bebo and Linkedin, are now commonly used by people to share their interests, views and activities with others. Although these and other social networking sites are a recent approach to communication they supersede the generation of chat rooms that were criticised earlier in the $21^{\text {st }}$ century for sexual exploitation (Jochan, Valenburg \& Schouten, 2006; Subrahmanyam, Smahel \& Greenfield, 2006; Toomey \& Rothenberg, 2000; Wolak, 
Finkelhor \& Mitchell, 2004). However, chat rooms were also welcomed in their role for increasing communication and identity (Subrahmanyam, Greenfield \& Tynes, 2004) and through the online advice for teenagers relating to health and sexuality (Suzuki \& Calzo, 2004). It is therefore not surprising that young people are using computers as a form of education and learning. Indeed, computers can provide effective sexual-health education via different intervention programs (Fong, Zanna \& Elton-Marshall, 2006; Goold et al. 2005; Keller \& La Belle, 2005; Yom \& Lee, 2005) and by challenging young people's knowledge via computer games (Alemi, Cherry \& Meffert, 1989; Bay-Cheng, 2001; Paperny \& Starn, 1989; Starn \& Paperny, 1990). Although computers have been useful in certain sexual-health campaigns, there is a lack of research on how these campaigns relate or contribute towards the sex and relationship (SRE) curriculum delivered within schools.

In the United Kingdom (UK) the Department of Children, Families and Schools (DCFS), is responsible for developing the most recent guidance and implementing current legislation for SRE within primary and secondary schools (DiCenso, Guyatt, \& Willan, 2002). The SRE guidance indicates how schools in England should deliver effective sex-education programs, and schools are strongly encouraged to follow these recommendations (DfEE, 2000). According to the Office for Standards in Education (Ofsted, 2002), the SRE guidance is recognised and regarded as good practice in that it forms the basis for good-quality sex education. Although Ofsted has a comprehensive system of inspection and regulation that corresponds with the British government's aim to provide better and more effective SRE to young people, Ofsted also recommends that schools should take a unified approach to teaching SRE with the support of healthcare professionals and, more important, the involvement of parents. 
Although schools are encouraged to involve parents in the SRE they deliver, previous research has suggested that some parents demur from discussing particular topics (e.g. sexuality) with their children (Gabb, 2004; Jordan, Price \& Fitzgerald, 2000; Kakavoulis, 2001), especially fathers (Goldman and Bradley, 2004; Kirkman, Rosenthal \& Feldman, 2003; Lefkowitz, Roma, Corona, Au \& Sigman, 2000a; Lehr, Demi, Dilorio, \& Facteau, 2005; Miller, Dilorio \& Dudley, 2002). It has been suggested that parents feel unable to discuss these topics, such as sexuality, as they fear that they are not equipped with both the necessary skills and the knowledge to educate their children (WernerWilson \& Fitzharris, 2001).

In the UK many myths, misconceptions and taboo subjects are associated with some sexual topics (Krafchick \& Biringen, 2002). These have existed for generations and to a certain extent still exist today. For example, a survey commissioned by the DCSF in 2009 revealed that from 2,000 people aged 16 to $50,11 \%$ thought that a women cannot get pregnant when standing up; $19 \%$ of women were not aware they could get pregnant whilst on their period; $37 \%$ of people never talk about contraception; $27 \%$ revealed being too embarrassed to ask questions relating to sexual issues and $25 \%$ expressed they wished that they could talk more openly about sex and relationships. This illustrates that the embarrassment and ignorance of British people is still apparent. This is especially so compared to other countries such as Germany, France and the Netherlands, who are more liberal and talk about sexual topics openly (Lewis \& Knijn, 2001) and who benefit from having relatively low numbers of teenage pregnancies, abortions and sexually transmitted infections (van Loon, 2003). Although open communication in these countries has been found to be successful specific parent programs that utilise computers have also been effective in the Netherlands (van Loon, 2003) and in the USA (Klein, 2000; Santelli, 
Otta, \& Lyon, 2006). However, it is important to identify if these types of programs would be useful in the UK when educating parents so that they can teach their own children about sexual matters. Therefore, the aim of the current study was to investigate the impact that computers can have on education and secondly, inform the development of a communication model of SRE that can be used within British families.

\section{Method and procedures}

A mixed-method methodology approach was taken for the present study. Triangulation of data was achieved by combining both qualitative (semi-structured interview) and quantitative methods (sexual-knowledge questionnaire). The qualitative data utilised Strauss and Corbin's (1990) Grounded Theory Method to build a theoretical analysis of the data collected. The data for this were collected by asking a series of open-ended questions to parents and their children regarding the SRE they received and the factors concerning the potential facilitators and barriers to communication about sexual matters within families. There were two different interview processes: in half of the families parents and their children were interviewed separately and in the other half together as a family. In contrast, the quantitative data were gathered using a 20 -item questionnaire that uncovered respondents' knowledge (using multiple-choice items with four options each) as well as confidence in their own knowledge (as a percentage). This assessed the sexual knowledge of parents and children's at three different stages of data collection (preintervention, post-intervention and follow-up) when utilising a multimedia program entitled 'Sense, Sex and Relationships'. The multimedia program was an appropriate resource as it covered all aspects of SRE that should be taught based on the DCFS legislation to young people aged 12 to 16 years. It covered aspects of puberty, contraception, STIs, pregnancy, sex and relationships whilst also providing main facts on 
how schools should teach SRE and how parents could increase communication of sexual matters with their children. To illustrate the study design and process a diagrammed conceptual framework is provided in Figure 1.

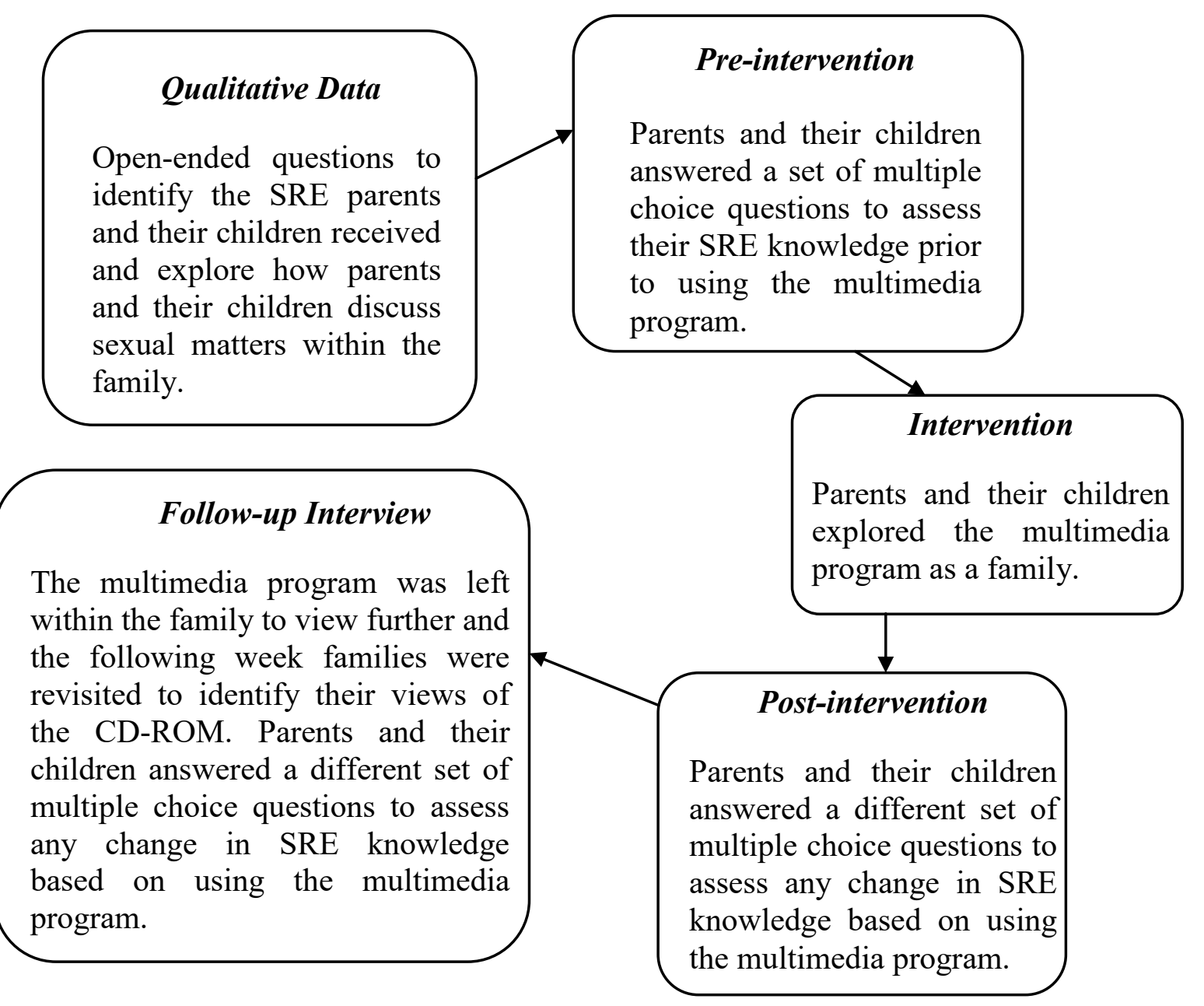

Figure 1 - Diagrammed conceptual framework of study design and process

Data were successfully analysed from pairs of families based on the constant comparative method of Strauss and Corbin's grounded theory method to identify any similarities or differences within the data. After each analysis open-ended questions were added where appropriate to further explore the phenomenon in subsequent interviews. Although only 20 families participated in the research, saturation of data collection had been reached and no new findings emerged. The findings from this research are discussed, giving an 
account of both the quantitative and qualitative data to illustrate how useful computers can be at increasing communication of SRE topics within families.

\section{Results}

In relation to the quantitative data, $2 x(3)$ analysis of variance (ANOVA) was employed to assess the effects of interview procedure and time on mothers' $(\mathrm{n}=20)$ knowledge and confidence in their sexual knowledge. The effect of time was significant but the effect of interview procedure and the interaction effect were not (see Tables 1 and 2). The increase in knowledge was significant from the pre-intervention to the postintervention stage (mean difference $=2.14, p=0.037$ ), and from the pre-intervention-to the follow-up stage (mean difference $=2.86, p=0.025$ ).

Table 1 - ANOVA summary table - Knowledge (mothers)

\begin{tabular}{lrccccc}
\hline Source & $d f$ & Sum of Squares & Mean Square & $\varepsilon^{2}$ & $F$ & $p$ \\
\hline Interview procedure & 1 & 13.61 & 13.61 & 0.00 & 0.89 & 0.36 \\
Error (procedure) & 18 & 275.51 & 15.31 & & & \\
Time & 2 & 88.44 & 44.22 & 0.13 & $6.50<0.001$ \\
Procedure $\times$ Time & 2 & 6.80 & 3.40 & 0.00 & 0.50 & 0.61 \\
Error (time) & 36 & 244.90 & 6.80 & & & \\
Total & 59 & 629.25 & & & & \\
\hline
\end{tabular}

The increase in confidence in mothers' own knowledge was also significant from the preintervention to the post-intervention stage (mean difference $=3.88, p=0.03$ ), and from the pre-intervention- to the follow-up stage (mean difference $=4.47, p=0.01$ ). \# 
Table 2 - ANOVA summary table - Confidence (mothers)

\begin{tabular}{lrccccc}
\hline Source & $d f$ & Sum of Squares & Mean Square & $\varepsilon^{2}$ & $F$ & $p$ \\
\hline Interview procedure & 1 & 0.23 & 0.23 & 0.00 & 0.01 & 0.93 \\
Error (procedure) & 18 & 459.64 & 25.54 & & & \\
Time & 1.10 & 235.92 & 214.47 & 0.19 & 9.42 & $<0.05$ \\
Procedure $\times$ Time & 1.10 & 7.60 & 6.91 & 0.00 & 0.30 & 0.60 \\
Error (time) & 19.84 & 450.60 & 22.72 & & & \\
Total & 41.04 & 1153.99 & & & & \\
\hline
\end{tabular}

Note: Some $d f$ are fractional to adjust for a lack of sphericity

No statistical inference on fathers' data was conducted, as too few participated.

However, the descriptive statistics showed an increase in knowledge and confidence in knowledge over time.

With $2 \times 2 \times(3)$ ANOVA, the effects of gender, interview procedure and time on children's (15 boys' and 10 girls') knowledge and confidence in their own knowledge was also assessed. The effect of time was significant but the main effects of gender and interview procedure, and the interaction effects were not (see Tables 3 and 4). There was a significant increase in knowledge from the pre-intervention- and post-intervention stage (mean difference $=10.83, p=0.03$ ), from the pre-intervention- to the follow-up stage (mean difference $=15.78, p=0.004)$, and from the post-intervention- to the follow-up stage (mean difference $=4.95, p=0.005$ ).

Table 3 - ANOVA summary table - Knowledge (children)

\begin{tabular}{lcccccc}
\hline Source & $d f$ & Sum of Squares & Mean Square & $\varepsilon^{2}$ & $F$ & $p$ \\
\hline Interview procedure & 1 & 2742.24 & 2742.24 & 0.07 & 3.61 & 0.07 \\
Gender & 1 & 291.04 & 291.04 & 0.00 & 0.38 & 0.54 \\
Procedure x Gender & 1 & 335.11 & 335.11 & 0.00 & 0.44 & 0.51 \\
Error (BS) & 21 & 15967.46 & 760.36 & & &
\end{tabular}




$\begin{array}{lrrrrrr}\text { Time } & 1.16 & 3046.39 & 2626.20 & 0.10 & 11.19 & <0.001 \\ \text { Procedure x Time } & 1.16 & 493.60 & 425.52 & 0.01 & 1.48 & 0.20 \\ \text { Gender x Time } & 1.16 & 63.69 & 54.91 & 0.00 & 0.23 & 0.67 \\ \text { Procedure x Gender } & & & & & & \\ \text { x Time } & 1.16 & 12.52 & 10.80 & 0.00 & 0.05 & 0.87 \\ \text { Error (time) } & 24.25 & 5715.30 & 235.72 & & & \\ \text { Total } & 53.89 & 28667.35 & & & & \end{array}$

Note: Some $d f$ are fractional to adjust for a lack of sphericity

The increase in children's confidence in their own knowledge was also significant for children from the pre-intervention- to the post-intervention stage (mean difference $=$ 12.50, $p<0.001$ ), from the pre-intervention- to the post-intervention stage (mean difference $=17.86, p<0.001)$ and from the post-intervention- to follow-up stage (mean difference $=15.78, p<0.014$ ). These findings suggest that the multimedia program was beneficial, in terms of providing good-quality sex education within families.

Table 4 - ANOVA summary table - Confidence (children)

\begin{tabular}{|c|c|c|c|c|c|c|}
\hline Source & $d f$ & Sum of Squares & Mean Square & $\varepsilon^{2}$ & $F$ & $p$ \\
\hline Interview procedu & ure & 2875.16 & 2875.16 & 0.05 & 2.70 & 0.12 \\
\hline Gender & 1 & 37.369 & 37.69 & 0.00 & 0.04 & 0.85 \\
\hline Procedure $\mathrm{x}$ gend & ler & 320.06 & 320.06 & 0.00 & 0.30 & 0.99 \\
\hline Error (BS) & 21 & 22333.08 & 1063.48 & & & \\
\hline Time & 1.20 & 3927.67 & 3273.06 & 0.11 & 20.80 & $<0.00$ \\
\hline Procedure $\mathrm{x}$ Time & e 1.20 & 222.02 & 185.02 & 0.00 & 1.18 & 0.30 \\
\hline Gender x Time & 1.20 & 120.45 & 100.38 & 0.00 & 0.64 & 0.46 \\
\hline \multicolumn{7}{|c|}{ Procedure $\mathrm{x}$ gender } \\
\hline$x$ time & 1.20 & 64.58 & 53.82 & 0.00 & 0.34 & 0.61 \\
\hline Error (time) & 25.52 & 3966.33 & 155.41 & & & \\
\hline Total & & 33866.72 & & & & \\
\hline
\end{tabular}

Note: Some $d f$ are fractional to adjust for a lack of sphericity

The findings of grounded-theory analysis complimented the quantitative results. Again, computers were found to act as a facilitator for providing good-quality SRE within British families. Although it was found that parents talked to their children about sexual 
matters it was found that this communication increased if children perceived their parents to be knowledgeable. This, coupled with an increase in confidence, allowed for greater communication of sexual matters within families when using computers to learn about SRE topics. Although parents and their children expressed the beneficial use of using computers to increase communication of sexual matters they also reported upon the usability, contents and effectiveness of using the multimedia program. In relation to usability one son (aged 15) in particular reported:

"I think for me it was the way it was all laid out, it looked really smart and something that would appeal to young people. It also gives a lot of valuable information and advice”. A mother also commented on the usability and contents of the multimedia program by stating:

"I think it was really good. The more sections you go through the better it gets ...I liked every aspect of it, but I think it was really good in that it was like a soap opera when showing you the different situations young people can find themselves in.”

In relation to effectiveness one son in particular reported:

"I talk to mum and dad about sex, but I liked it when we went through the CD together because it allowed me to ask questions that I wouldn't have without the prompts on the CD”.

A mother also gave an example of how useful and effective the multimedia program was in increasing communication about condoms with her son. The mother reported:

"I thought we had discussed most things, but then when I think about it afterwards we have mainly only discussed the condom and not the pill ... I mean we have discussed condoms, but not other contraception in relation to girls as well ... I am pleased we have discussed contraception from both sexes now, but that just goes to show how useful the 
$\mathrm{CD}$ has been to us. It has generated conversations so I can educate him and give him all the information that he wants and possibly needs in future, especially in relation to contraception".

Although these quotes clearly state the satisfaction associated with using the multimedia program, in particular the use of computers to increase knowledge and communication within families, the grounded-theory analyses also identified other factors that increased communication about sexual matters. In particular, communication was better when children had respect, trust and perceived their parents as a role model. Barriers that prevented communication of sexual matters were parents being embarrassed when discussing sexual matters because they did not have the knowledge and skills to educate their own children. Religion and parents being inquisitive of their children's knowledge also acted as a barrier because children perceived their parents to be asking personal questions that were invasive of their personal life and personal relationships. This was in fact due to parents not being aware of the SRE given by schools. These factors, together with the benefits that computers can bring, should all be considered in a comprehensive approach to SRE.

\section{Discussion and conclusions}

One of the most important findings from this research is that computers can be beneficial at increasing discussions of SRE topics within British families. This was even so in families who had previously discussed sexual matters, as the contents of the computer program generated further conversations, adding to SRE topics that had already been discussed. This finding emphasises that parents can and do discuss sexual matters openly with their children and vice versa. However, these conversations were more likely to occur if children perceived their parents to have the knowledge about SRE topics to teach 
them. The computer program had dual benefits in that it did not only contribute towards family discussions, but it educated parents and their children to be more open about SRE topics. Moreover, it was found that over three successive stages involving the use of computer-supported SRE (pre-intervention, post-intervention and follow-up) parents' and their children's knowledge and confidence in their own knowledge increased. Although the computer program was shown to be a beneficial resource in educating family members, embarrassment, lack of knowledge and invasion of privacy were also found to affect communication regarding sexual matters.

Grounded-theory analysis supported previous literature to suggest that parents may demur from discussing sexual topics if they do not have the skills and knowledge to do so (Werner-Wilson \& Fitzharris, 2001). Therefore, there is a need for parent-programs so parents can teach their own children (Turnbull, van Wersch \& van Schaik, 2008). However, schools need to follow the recommendations of the SRE Guidance (DfEE, 2000) by involving parents in the SRE given to their children. This would then allow parents to become equipped with the knowledge needed to educate their children further based on the SRE given at school, and the findings of the current study indicate that computers can play a useful role in this education.

Although the Internet has been found to be engulfed with pornographic material and seductive images (Richardson, 2009), computers have been shown to be purposeful in educating young people about sexual matters (Bay-Cheng, 2001; Fong, Zanna \& Elton-Marshall, 2006; Goold et al. 2006; Keller \& La Belle, 2005; Yom \& Lee, 2005). This was further demonstrated in the present investigation which, unlike the Internet, provided children with sexual facts and sexual information needed to make informed choices over their sexual relationships and sexual behaviour. In this instance computers 
were found to enhance and influence SRE conversations between parents and their children, but also to increase knowledge.

Although this investigation has raised important issues that are related to SRE in British families, limitations exist relating to the findings. A first limitation relates to extension of the findings to a wider population given that the research used a sample from a small area of the North East of England. Secondly, given the mixed-method nature and focus of the current study, control groups (one not using computers for SRE and another without any intervention) were not included. Therefore, the effects of computer support and intervention were confounded with other aspects of the intervention and the 'natural' process of SRE over time.

\section{Future research}

Future research may consider extending upon these findings and exact precisely what support, including the use of computers for SRE, the government can give to support parents, so they can become knowledgeable and educate their own children. This work would, furthermore, build upon family relationships and increase communication of not only sexual matters, but also other sensitive subjects that may arise in families, now, and in the future.

\section{References}

Alemi, F., Cherry, F., \& Meffert, G. (1989). Rehearsing decisions may help teenagers: An evaluation of a simulation game. Computer Biology, 19(4), 283-290.

Bay-Cheng, L. (2001). SexEd.com: Values and norms in web-based sexuality education. The Journal of Sex Research, 38(3), 241-251.

Department for Children, Schools and Families. (2009). Poll lays bare myths of 'safe sex’. United Kingdom Press Association. 
Department for Education and Employment. (2000). Sex and Relationship Education Guidance (0116/2000). (London: HMSO).

DiCenso, A., Guyatt, G., \& Willan, A. (2002). Review: Primary prevention strategies do not delay initiation of intercourse, improve contraceptive use, or reduce pregnancies in adolescent women. Evidence-Based Nursing, 6, 13.

Fong, G.T., Zanna, M.P., \& Ellen-Marshall, T.E. (2006). Remembering the message: The use of a reminder cue to increase condom use following a safer sex intervention. Health Psychology, 25(3), 438-443.

Foster-Cox, M., Scharer, K. \& Clark, A.J. (2009). Development of a Web-Based Program to Improve Communication about Sex. Computers, Informatics, and Nursing. $27(1), 18-25$.

Gabb, J. (2004). Sexuality education: How children of lesbian mother 'learn' about sexuality. Sex Education, 4(1), 19-34.

Goold, P.C., Bustard, E.F., Carlin, E.M., Neal, K., \& Bowman, C.A. (2006). Pilot study in the development of an interactive multimedia learning environment for sexual health interventions: A focus group approach. Health Education Research: Theory \& Practice, 21(1), 15-25.

Goldman, J.D.J., \& Bradley, G.L. (2004). Parents as sexuality educators of their children in the technological age. Australian Journal of Guidance \& Counselling, 14(2), 233-250.

Haggstrom-Nordin, E., Sandberg, J., Hanson, U., \& Tyden, T. (2006). 'Its everywhere!': Young Swedish people thoughts and reflections about pornography. Scandinavian Journal of Caring Service, 20(4), 386-393. 
Jochen, P., Valkenburg, P.M., \& Schouten, A.P. (2006). Characteristics and motives of adolescents talking with strangers on the Internet. CyberPsychology \& Behavior, 9(5), 526-530.

Johnson, R. (2008). Hardcore porn made easy. The Times, October 5, 2008.

Jordan, T.R., Price, J.H., \& Fitzgerald. (2000). Rural parents communication with their teenagers about sexual issues. Journal of School Health, 70, 338-344.

Kirkman, M., Rosenthal, D.A., \& Feldman, S.S. (2003). Talking to a Tiger: Fathers Reveal Difficulties in Communicating About Sexuality with Adolescents. San Francisco, CA: Jossey-Bass.

Keller, S.N., \& La Belle, H. (2005). STDs.com: Sexuality education online. Education and Health, 23(1), 10-11.

Klein, M. (2000). Coming Attractions: Sexual Expressions in the New Decade. SIECUS Report, 28(2), 9.

Krafchick, J., \& Biringen, Z. (2002). Parents as sexuality educators: The role of family therapists in coaching parents. Journal of Feminist Family Therapy, 14(3/4), 5772.

Lefkowitz, E.S., Roma, L.F., Corona, R., Au, T.K., \& Sigman, M. (2000a). How Latino American and European adolescents discuss conflicts, sexuality, and AIDS with their mothers. Developmental Psychology, 36, 315-325.

Lehr, S.T., Demi, A.S., Dilorio, C., \& Facteau, J. (2005). Predictors of father-son communication about sexuality. Journal of Sex Research, 42(2), 119-129.

Lewis, J., \& Knijn, T. (2001). A comparison of English and Dutch sex education in the classroom. Education and Health, 19(4), 59-64. 
Miller, J.M., Dilorio, C., \& Dudley, W. (2002). Parenting style and adolescent's reaction to conflict: Is there a relationship? Journal of Adolescent Health, 31(6), 463-468.

Office for National Statistics. (2008). Internet Access 2007: Households and Individuals. London: HMSO.

Office for Standards in Education. (2002). Sex and Relationships. London: Ofsted.

Paperny, D., \& Starn, J. (1989). Adolescent pregnancy prevention by health education computer games: Computer-assisted instruction of knowledge and attitudes. Paediatrics, 83, 742-752.

Richardson, A. (2009). The sex education roadshow vs. pornography. $30^{\text {th }}$ March, 2009, Channel 4. Available at: www.sexexperienceuk.channel4.com

Santelli, J., Ott, M.A., Lyon, M., Rogers, J., \& Summers, D. (2006). Abstinence and abstinence-only education: A review of U.S. Policies and programs. Journal of Adolescent Health, 38, 72-81.

Starn, J. \& Paperny, D.M. (1990). Computer games to enhance adolescent sex education. The American Journal of Maternal Child Nursing, 15, 250-253.

Strauss, A., \& Corbin, J. (1990). Basics of Qualitative Research: Grounded Theory Procedures and Techniques. London: Sage.

Subrahmanyam, K., Greenfield, P.M., \& Tynes, B. (2004). Constructing sexuality and identity in an online teen chat room. Applied Developmental Psychology, 25, 651666.

Subrahmanyam, K., Smahel, D., \& Greenfield, P. (2006). Connecting developmental constructions to the Internet: Identity presentation and sexual exploration in online teen chat rooms. Developmental Psychology, 42(3), 395-406. 
Suzuki, L.K., \& Calzo, J.P. (2004). The search for peer advice in cyberspace: An examination of online teen bulletin about health and sexuality. Applied Developmental Psychology, 25, 685-698.

Toomey, K.E., \& Rothenberg, R.B. (2000). Sex and cyberspace - Virtual networks leading to high-risk sex. The Journal of the American Medical Association, 284(4), 485-487.

Turnbull, T., van Wersch, A., \& van Schaik, P. (2008). A review of parental involvement in sex education: The role for effective communication in British Families. Health Education Journal, 67(3), 182-195.

Van Loon, J. (2003). Deconstructing the Dutch Utopia: Sex education and teenage pregnancy in the Netherlands. London: Family Education Trust.

Werner-Wilson, R.J., \& Fitzharris, J.L. (2001). How can mothers and fathers become involved in the sexuality education of adolescents? Journal of HIV/AIDS Prevention \& Education for Adolescents \& Children, 4(1), 49-59.

Wolak, J. Finkelhor, D., \& Mitchell, K. (2004). Internet- initiated sex crimes against minors: Implications for prevention based on findings from a National study. Journal of Adolescent Health, 35, 424.e11-424.e20.

Yom, Y.E., \& Lee, K. (2005). Effects of a CD-ROM educational program on sexual knowledge and attitude. Computers in Nursing, 23(4), 214-219. 